\title{
Effect of Metal Dispersion on the Hydrogenation of 2-Amyl Anthraquinone over $\mathrm{Pd} / \mathrm{Al}_{2} \mathrm{O}_{3}$ Catalyst
}

\author{
Xiaotong Li, ${ }^{a, b}$ Hongjiu Su, ${ }^{a}$ Gaoyuan Ren ${ }^{a}$ and Shudong Wang $* a$ \\ ${ }^{a}$ Dalian Institute of Chemical Physics, Chinese Academy of Sciences, 116023 Dalian, Liaoning, China \\ ${ }^{b}$ University of Chinese Academy of Sciences, 100039 Beijing, China
}

\begin{abstract}
A series of highly dispersed $\mathrm{Pd} / \mathrm{Al}_{2} \mathrm{O}_{3}$ catalysts were prepared via the polyol method. The catalysts were characterized by nitrogen adsorption, X-ray diffraction (XRD), UV-Vis spectrophotometry, temperature programmed reduction (TPR) and transmission electron microscopy (TEM). The influence of Pd particle size on the hydrogenation of 2-amyl anthraquinone (AAQ) was investigated in a trickle-bed reactor. The turnover frequency (TOF) showed antipathetic size dependence while the space time yield (STY) peaked at $4 \mathrm{~nm}$. Also, the selectivity and deactivation rate were affected by the size of palladium particles. The structure-sensitivity relations for the catalysts may be ascribed to the necessities of specific Pd cluster structure for the activation of $\pi$-bond.
\end{abstract}

Keywords: anthraquinone hydrogenation, $\mathrm{H}_{2} \mathrm{O}_{2}$, dispersion

\section{Introduction}

Hydrogen peroxide $\left(\mathrm{H}_{2} \mathrm{O}_{2}\right)$ is widely used in the chemical industry and environmental protection as an environmentally friendly oxidant. ${ }^{1-3}$ Today, hydrogen peroxide is manufactured almost exclusively by the autoxidation of 2-alkyl anthrahydroquinone (2-alkyl $\mathrm{AQH}_{2}$ ) to the corresponding 2-alkyl anthraquinone (2-alkyl AQ) in the so-called AQ process. In the cyclic process, AQ is hydrogenated to yield anthrahydroquinone, then oxidation of the latter produces hydrogen peroxide and regenerates the starting AQ (Scheme 1). ${ }^{4}$ Major producers commonly use either the 2-ethyl or the 2-amyl derivative of AQ. In recent years, along with the production growth of downstream products such as propylene oxide and caprolactam, the market demand for $\mathrm{H}_{2} \mathrm{O}_{2}$ solution at high concentration has been increasing substantially. Given its high solubility, 2-amylanthraquinone is considered as a good replacement for the widely used 2-ethylanthraquinone to increase productivity. ${ }^{5}$ The network of the reactions taking place during the hydrogenation of 2-amyl anthraquinone (AAQ) is quite complicated. The desired products considered as active anthraquinones are 2-amyl anthrahydroquinone $\left(\mathrm{AAQH}_{2}\right)$ and 2-amyl tetrahydroanthrahydroquinone $\left(\mathrm{H}_{4} \mathrm{AAQH}_{2}\right)$, which could produce $\mathrm{H}_{2} \mathrm{O}_{2}$ after oxidation. However, other degradations such as 2-amyl octahydroanthrahydroquinone

*e-mail: wangsd@dicp.ac.cn
$\left(\mathrm{H}_{8} \mathrm{AAQH}{ }_{2}\right)$ and anthrone (AN) are useless to the $\mathrm{H}_{2} \mathrm{O}_{2}$ production. ${ }^{6}$ Previous literature about the hydrogenation of anthraquinone used the 2-ethyl-anthraquinone (EAQ) system rather than the 2-amylanthraquinone system. In addition, the research focused on the topics such as the enhancement of mass transfer and the properties of support. For example, Santacesaria et al. ${ }^{7}$ reported that the hydrogenation of 2-ethyl-anthraquinone over Pd catalysts was a fast reaction and the mass transfer of EAQ was the rate limiting step. Based on this, Luo and co-workers ${ }^{8}$ designed an egg shell $\mathrm{Pd} / \mathrm{glass}$ catalyst which can achieve a high instant yield of $\mathrm{H}_{2} \mathrm{O}_{2}$ of $11.2 \mathrm{~g} \mathrm{~L}^{-1}$. Besides, the acid-base property of the support was a key point to influence the catalyst activity and selectivity, as the acid sites of the support were considered as the adsorption sites of EAQ. The adsorbed EAQ molecules were subsequently activated and hydrogenated by spilled-over hydrogen species formed on metal surface. ${ }^{9}$ For example, Li and co-workers ${ }^{10}$ prepared a $\mathrm{Pd} / \mathrm{SiO}_{2}-\mathrm{Al}_{2} \mathrm{O}_{3}$ catalyst with proper acidity which can achieve $\mathrm{H}_{2} \mathrm{O}_{2}$ yield of $10.3 \mathrm{~g} \mathrm{~L}^{-1}$ in a slurry reactor. However, research about the size effect has not been reported.

Due to the catalytic property dependence upon surface structure that vary with particle size, synthesis of well-defined highly-dispersed particles now pave the way for the design of catalysts with desirable properties. ${ }^{11-13}$ Several papers have mentioned the relationship between particle size and reaction activity or selectivity. ${ }^{14-20}$ Catalytic dependence on surface structure in practical applications has different features. 


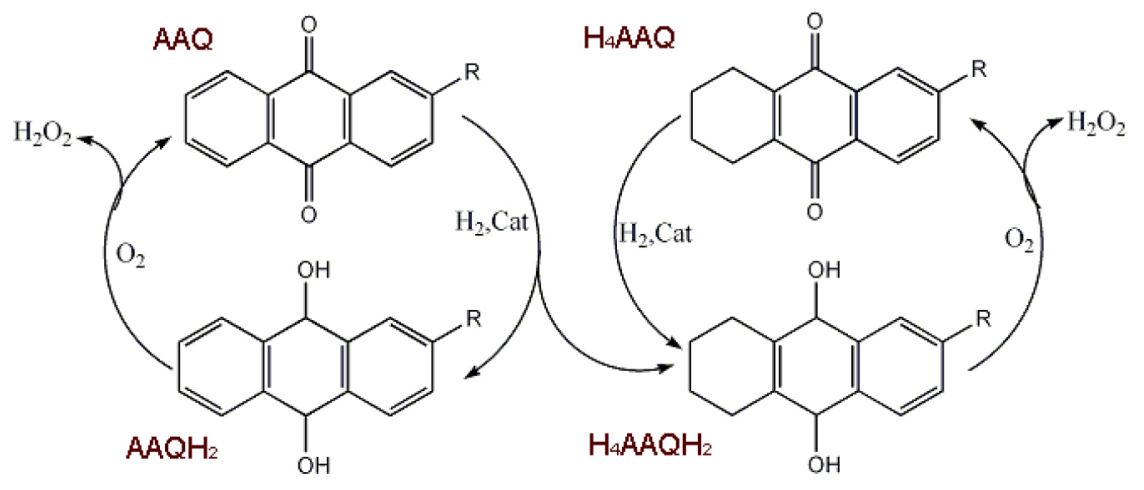

Scheme 1. Reaction network of the hydrogenation of amyl anthraquinone.

Usually, there are three types of surface sensitivity named class I, II and III. ${ }^{21}$ They represent circumstances when the intrinsic reaction rate (turnover frequency, TOF) (i) increases with the growth of particle size of active component (class I); (ii) decreases with the growth of particle size of active component (class II); and (iii) is independent of the growth of particle size of active component (class III). Class I surface sensitivity is also known as antipathetic size dependence, and a lot of literature explains the reasons. For instance, Hammer

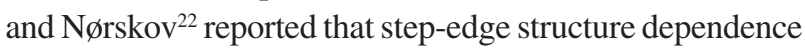
of dissociative adsorption is quite general for the cleavage of the $\pi$-bonds of diatomic molecules as $\mathrm{CO}, \mathrm{N}_{2}, \mathrm{O}_{2}$, or NO. Xiao et al. ${ }^{23}$ reported that the Fischer-Tropsch reaction was found to show class I behavior on $\mathrm{Ru} / \mathrm{SiO}_{2}$ catalyst. It formed long chain hydrocarbons from $\mathrm{CO}$ and the reaction rate decreased sharply when Ru particle sizes were below $2 \mathrm{~nm}$. Bielawa et al. ${ }^{24}$ reported that the special B5-type site, consisting of an arrangement of three Ru atoms in one layer and two further Ru in the layer directly above this at a monoatomic step on an $\mathrm{Ru}(001)$ terrace, is necessary for $\mathrm{N}_{2}$ dissociation. Honkala et al. ${ }^{25}$ reported a kind of unique step-edge type sites on particles with the shape of incomplete octahedra, and they identified the critical size for octahedral shape formation was around $2 \mathrm{~nm}$. In brief, the activation of the $\pi$-bonds needs metal clusters with a certain amount of atoms and specific packing structure which cannot form in small particles. Moreover, the variation tendency of apparent reaction rate differs from that of intrinsic reaction rate. For example, the smallest particles will own the maximum apparent rate per mass catalyst if the intrinsic rate increases with decreasing particle size, or is independent of it, while a maximum apparent rate per mass catalyst will occur at an intermediate particle size when TOF increases with increasing particle size. However, studies about surface sensitivity mainly focus on two-phase reaction such as $\mathrm{CO}$ oxidation $^{26}$ and acetylene selective hydrogenation ${ }^{27}$ rather than three-phase reaction, so the catalyst structure sensitivity in hydrogenation of AAQ has been rarely reported.
The aim of this work is to investigate the size effect of AAQ hydrogenation over highly-dispersed Pd particles in the size region of 1-7 nm. Precise Pd particle size control was achieved in a polyol method as Pd particles grow with the extension of reflux time and the raising of calcination temperature. The catalysts were characterized by nitrogen physisorption using the Brunauer-Emmett-Teller (BET) method, transmission electron microscopy (TEM), and temperature programmed reduction (TPR).The catalytic performance was measured in a trickle-bed reactor; the activity and selectivity were tested.

\section{Experimental}

Materials

Ethylene glycol, polyvinylpyrrolidone (PVP), $\mathrm{NaOH}$, $\mathrm{HNO}_{3}$, and $\mathrm{KMnO}_{4}$ (Sinopharm reagent Co.) were all analytical reagent (AR) grade and used without further purification. The concentration of $\mathrm{H}_{2} \mathrm{PdCl}_{4}$ aqueous solution is $20 \mathrm{mg} \mathrm{mL}^{-1}$ (by Pd weight). AAQ was supplied by Haiqu Chemical Co, Shanghai, China. $\mathrm{Al}_{2} \mathrm{O}_{3}$ was supplied by Supeng Co, Shanghai, China.

\section{Preparation of the catalyst}

The preparation method of the catalyst was as follows: $2 \mathrm{~g} \theta-\mathrm{Al}_{2} \mathrm{O}_{3}$ and $0.2 \mathrm{~g}$ PVP were dispersed into $160 \mathrm{~mL}$ ethylene glycol under nitrogen atmosphere. The $\mathrm{pH}$ value of the mixture was adjusted by introducing a $2 \mathrm{~mol} \mathrm{~L}^{-1}$ $\mathrm{NaOH}$-ethylene glycol solution until its $\mathrm{pH}$ value reached 10 under vigorous stirring. Then the mixture of $40 \mathrm{~mL}$ isopropyl alcohol and $1 \mathrm{~mL} \mathrm{H}_{2} \mathrm{PdCl}_{4}$ solution was added to ethylene glycol solution above dropwise. The suspension obtained was heated to $393 \mathrm{~K}$. After desired reaction time, $\mathrm{HNO}_{3}$ solution $\left(0.5 \mathrm{~mol} \mathrm{~L}^{-1}\right)$ was added into the cooled mixture until the $\mathrm{pH}$ value was 2 . Continuous stirring was needed for $12 \mathrm{~h}$. Then the product was washed repeatedly 
Table 1. Physicochemical characteristic of catalysts

\begin{tabular}{|c|c|c|c|c|c|c|}
\hline Sample & Reflux time / h & $\begin{array}{c}\text { Calcination } \\
\text { temperature / K }\end{array}$ & $\begin{array}{l}\text { Specific surface } \\
\text { area }^{\mathrm{a}} /\left(\mathrm{m}^{2} \mathrm{~g}^{-1}\right)\end{array}$ & Pd loading $/$ wt. $\%$ & $\mathrm{Size}^{\mathrm{c}} / \mathrm{nm}$ & Dispersion $^{\mathrm{d}} / \%$ \\
\hline A & 1 & 573 & 89.9 & 0.42 & 1.0 & 51.0 \\
\hline B & 3 & 573 & 84.7 & 0.51 & 2.7 & 43.1 \\
\hline $\mathrm{C}$ & 3 & 773 & 85.4 & 0.51 & 4.0 & 25.5 \\
\hline $\mathrm{D}$ & 6 & 773 & 81.9 & 0.66 & 6.9 & 17.2 \\
\hline $\mathrm{E}$ & 9 & 773 & 76.7 & 0.79 & 6.5 & 16.4 \\
\hline
\end{tabular}

a'Determined by BET method; ${ }^{\mathrm{b}}$ determined from UV-Vis analysis; ${ }^{\mathrm{c}}$ determined from TEM analysis; ${ }^{\mathrm{d}}$ calculated from TEM analysis.

with ethanol and ultrapure water until no chloride anions were detected. The obtained $\mathrm{Pd} / \mathrm{Al}_{2} \mathrm{O}_{3}$ catalysts were dried at $313 \mathrm{~K}$ for $12 \mathrm{~h}$ and calcined for $2 \mathrm{~h}$. Finally, the catalysts were reduced with $20 \mathrm{wt} . \%$ hydrazine hydrate. The preparation detail is shown in Table 1. The theoretical loading of Pd was $1 \mathrm{wt} . \%$ in all the samples.

\section{Catalyst characterizations}

Nitrogen adsorption was used to characterize specific surface areas of samples according to the BET method at the liquid $\mathrm{N}_{2}$ temperature with a Quantachrome NOVA 2200e instrument. Prior to analysis, the samples were degassed under vacuum at $573 \mathrm{~K}$ for at least $2 \mathrm{~h}$.

The X-ray diffraction (XRD) measurements were carried out on a Rigaku RINT D/MAX-2500/PC diffractometer with $\mathrm{Cu} K \alpha$ radiation at $40 \mathrm{~mA}$ and $40 \mathrm{kV}$. The operating parameters were $2 \theta$ ranges scanning from 10 to $90^{\circ}$, scan step size of $0.02^{\circ}$ and scan rate of $5^{\circ} \mathrm{min}^{-1}$.

The Pd loading of the catalyst was analyzed by the Jasco V-550 UV-Vis spectrophotometer. A standard curve $\mathrm{y}=39.479 \mathrm{x}$ was used (here $\mathrm{y}$ was the Pd content, $\mathrm{mg} \mathrm{L}^{-1}$, and $x$ was the absorbance, $R^{2}=0.999$ ). Before analysis, Pd supported on the catalysts was dissolved by aqua regia. Then the metal loading was calculated by absorbance value according to the standard curve.

The TEM measurement was carried out with JEOL JEM-2000 EX equipment operated at an accelerating voltage of $120 \mathrm{kV}$. The reduced catalyst sample was ultrasonically dispersed in ethanol and dropped onto a copper grid with amorphous carbon film, then dried in air.

The TPR experiments were performed on a flow system in a Quantachrome CHEMBET 3000 adsorption instrument equipped with a thermal conductivity detector (TCD) detector. A water trap removed moisture from the TPR effluent stream before the TCD. Prior to reduction, a certain amount of the as-prepared catalyst (normalized to $0.55 \mathrm{mg}$ Pd) was placed into a quartz reactor and dried in a He flow at $423 \mathrm{~K}$ for $1 \mathrm{~h}$. Then the sample was reduced in a $10 \mathrm{vol} \% \mathrm{H}_{2} / \mathrm{Ar}\left(30 \mathrm{~mL} \mathrm{~min}^{-1}\right)$ flow system at a rate of $10 \mathrm{~K} \mathrm{~min}^{-1}$ from 373 to $423 \mathrm{~K}$.

\section{Catalytic activity test}

The activity test was carried out in a stainless steel trickle-bed reactor $(\phi 4 \times 150 \mathrm{~mm})$ at $318 \mathrm{~K}$ with $0.25 \mathrm{~g}$ catalyst, under $0.4 \mathrm{MPa}$ pressure of hydrogen. The liquid feeding speed was $0.3 \mathrm{~mL} \mathrm{~min}^{-1}$, and the feeding speed ratio of gas and liquid $(\mathrm{G} / \mathrm{L})$ was 10:1. The liquid hourly space velocity (LHSV) was $48 \mathrm{~h}^{-1}$. The working solution was prepared by dissolving $225 \mathrm{~g}$ of solid AAQ in $1 \mathrm{~L}$ of a mixed solvent of trioctyl phosphate (TOP) and trimethylbenzene (TMB) with the volume ratio of 1:3. Every other hour, $5 \mathrm{~mL}$ of catalyst-free hydrogenation products were oxidized with air at room temperature. $\mathrm{H}_{2} \mathrm{O}_{2}$ was then extracted with deionized water to obtain a solution of $\mathrm{H}_{2} \mathrm{O}_{2}$. The content of $\mathrm{H}_{2} \mathrm{O}_{2}$ was analyzed by titration with $\mathrm{KMnO}_{4}$ solution. The products were analyzed by high-performance liquid chromatography (HPLC) with an Agilent 1100 HPLC, equipped with a column of Kromasil C18; the mobile phase was methanol and water with a ratio of $3: 1$.

The catalyst activity and selectivity are expressed by the following simplified equations:

$$
\begin{aligned}
& x=\frac{B}{M_{\mathrm{H}_{2} \mathrm{O}_{2}} \times c_{A Q}} \times 100 \% \\
& B=\frac{5 c_{K M n O_{4}} \times V_{K M n O_{4}} \times M_{\mathrm{H}_{2} \mathrm{O}_{2}}}{2 V} \\
& S T Y=\frac{B \times F \times 60 \times 24}{1000 \times m_{c a t} \times c_{P d}} \\
& T O F=\frac{c_{A Q} \times F \times t \times x}{\frac{m_{c a t} \times c_{P d}}{M_{P d}} \times D \times 1000} \\
& S=\frac{n_{(A A Q)}+n_{\left(H_{4} A A Q\right)}}{n_{0(A A Q)}} \times 100 \%
\end{aligned}
$$


where $\mathrm{x}$ is the $\mathrm{AQ}$ conversion; $\mathrm{B}$ is the hydrogenation efficiency $\left(\mathrm{g} \mathrm{L}^{-1}\right) ; \mathrm{M}_{\mathrm{H}_{2} \mathrm{O}_{2}}$ is the molar mass of $\mathrm{H}_{2} \mathrm{O}_{2} ; \mathrm{C}_{\mathrm{KMnO}_{4}}$ and $\mathrm{c}_{\mathrm{AQ}}$ are the concentration $\left(\mathrm{mol} \mathrm{L}^{-1}\right)$ of $\mathrm{KMnO}_{4}$ and $\mathrm{AAQ}$ solution, respectively; $\mathrm{V}_{\mathrm{KMnO}}$ is the $\mathrm{KMnO}_{4}$ solution volume $(\mathrm{mL})$ and $\mathrm{V}_{\mathrm{H}_{2} \mathrm{O}_{2}}$ is the $\mathrm{H}_{2} \mathrm{O}_{2}$ solution volume $(\mathrm{mL})$; $\mathrm{STY}$ is the space time yield per gram palladium $\left(\mathrm{kg}_{\mathrm{H} 2 \mathrm{O} 2} \mathrm{~g}^{-1}{ }_{\mathrm{Pd}} \mathrm{d}^{-1}\right)$; $\mathrm{F}$ is feeding speed of working solution $\left(\mathrm{mL} \mathrm{min}^{-1}\right)$; $\mathrm{c}_{\mathrm{Pd}}$ and $\mathrm{m}_{\text {cat }}$ are Pd loading (wt.\%) and catalyst mass (g), respectively; TOF is the turnover frequency (number of molecules formed per active site per hour, $\left.\mathrm{h}^{-1}\right)$; $\mathrm{t}$ is the feeding time ( $\mathrm{min}$ ); $\mathbf{M}_{\mathrm{Pd}}$ is the molar mass of palladium; $\mathrm{D}$ is the Pd dispersion; $\mathrm{s}$ is the selectivity toward active quinones; $\mathrm{n}_{0}$ and $\mathrm{n}$ are the molar content of components in the initial working solution and in the solution accumulated in each hour, respectively.

\section{Results and Discussion}

\section{Characterization}

The preparation parameters of catalysts A-E and their characteristics are listed in Table 1. Pd loadings of catalysts A-E are proportional to reflux time which indicates that $\mathrm{Pd}$ progressively deposits onto the support. Furthermore, the deposition velocity of $\mathrm{Pd}$ nanoparticles onto $\mathrm{Al}_{2} \mathrm{O}_{3}$ substrate is uniform after $1 \mathrm{~h}$. This suggests that the final Pd loading is controlled by the deposition time. Besides, as the pretreatment temperature of $\mathrm{Al}_{2} \mathrm{O}_{3}$ support is higher than $773 \mathrm{~K}$, the latter calcinations at $573 \mathrm{~K}$ and $773 \mathrm{~K}$ should have no effect on the specific surface area. Hence, it can be inferred that the specific surface area of catalysts decreases with the increasing reflux time. It is due to that more $\mathrm{Pd}$ deposits on the $\mathrm{Al}_{2} \mathrm{O}_{3}$ support with longer reflux time, which may cause the loss of specific surface area. The loss of surface area can be attributed to the coverage of pores upon introducing $\mathrm{Pd}$.

Figure 1 shows the powder XRD patterns of $\mathrm{Al}_{2} \mathrm{O}_{3}$ substrate powder and catalyst E. Peaks at approximately $31.4,32.8,36.6,66.5$ and $67.2^{\circ}$ showing up in the XRD pattern of $\mathrm{Al}_{2} \mathrm{O}_{3}$ substrate powder are attributed to the (400), (002), (111), (021) and (512) reflections of $\theta-\mathrm{Al}_{2} \mathrm{O}_{3}$ (Joint Committee on Powder Diffraction Standards (JCPDS) 86-1410), respectively. However, Pd peaks located at 40.2 and $46.8^{\circ}$ (JCPDS 87-0638) are not detected in the XRD pattern of catalyst E, due to the Pd content of the catalyst being too low to be detected. Also, the Pd is well dispersed.

Figures 2a-e show the representative TEM images of five catalysts. The Pd particle size increases with the increasing reflux time and calcination temperature. From the TEM images, it can be seen that all the catalysts contained spherical particles with mean diameters in the range of

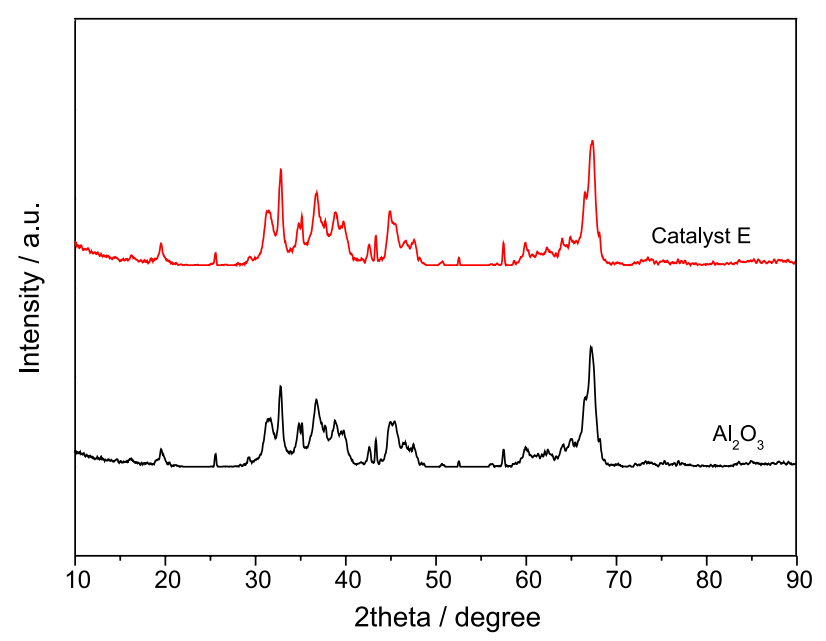

Figure 1. XRD patterns of (a) $\mathrm{Al}_{2} \mathrm{O}_{3}$ substrate powder and (b) catalyst $\mathrm{E}$.

1-7 $\mathrm{nm}$. The histograms of the particle size distribution indicate that lower calcination temperature contributed to a uniform size distribution. When the temperature is fixed, the Pd particle size increases with longer reflux time. Due to the high surface energy, the small supported particles become larger with the continuous deposition of the $\mathrm{Pd}$ nanoparticles from liquid to the support. However, when the Pd particle is larger than $6 \mathrm{~nm}$, its size remains the same with longer reflux time, which may be attributed to the decrease of surface energy of the Pd particles. As the particle size increases, the defects on the crystal surface decrease resulting in a lower surface energy. Besides the reflux time, the calcination temperature of catalysts is another factor influencing the Pd particle size. Comparing samples B with C, it can be concluded that the calcination temperature contributes to the growth of Pd particles, which can be ascribed to the migration and aggregation of Pd particles during calcination process. Also, the dispersion (Table 1, last column) is calculated by using a standard surface area-size relationship..$^{28}$

Figure 3 shows the $\mathrm{H}_{2}$-TPR profiles of the catalysts. As is known in literature, ${ }^{29}$ the reduction of supported PdO occurs at room temperature and only negative peaks will be observed in the $\mathrm{H}_{2}$-TPR profiles. In Figure 3, obvious negative peaks centered at $348 \mathrm{~K}$ appear in the profiles of samples C-E while the profiles of samples A and B are nearly straight lines. The formation of negative peaks is attributed to the $\mathrm{H}_{2}$ release due to the decomposition of the bulk palladium hydride formed at low temperature. ${ }^{30}$ Former literature reported that it was hard for the small particles to form the bulk palladium hydride. ${ }^{31}$ This observation is well corroborated by the TEM results. The peaks of the decomposition of $\beta$-palladium hydride in samples A and B are weak as the supported Pd particles are quite small. Also, it can be observed that the negative peak 

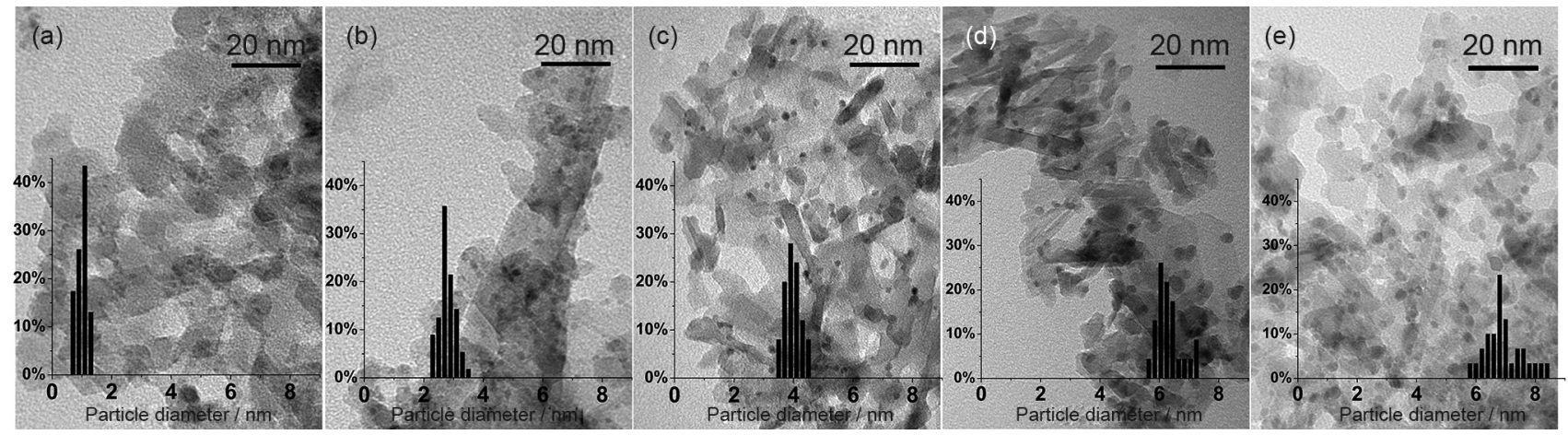

Figure 2. TEM images of catalysts (a) A, (b) B, (c) C, (d) D and (e) E. Inset: histograms of the Pd particle size distribution.

areas become larger suggesting $\mathrm{H}_{2}$ production promotion. As the total Pd mass of catalyst samples is normalized for $\mathrm{H}_{2}$-TPR test, it can be inferred that the $\mathrm{H}_{2}$ production is associated with the Pd particle sizes of catalysts C-E. As shown in Table 2, catalysts with larger Pd particles will release more $\mathrm{H}_{2}$ when the $\beta$-palladium hydride decomposes; however, catalyst samples A and B, with small Pd particles, also release less hydrogen to be detected. It is due to that the hydrogen absorption increased with the Pd particle sizes in $\beta$-palladium hydride formation. ${ }^{32}$

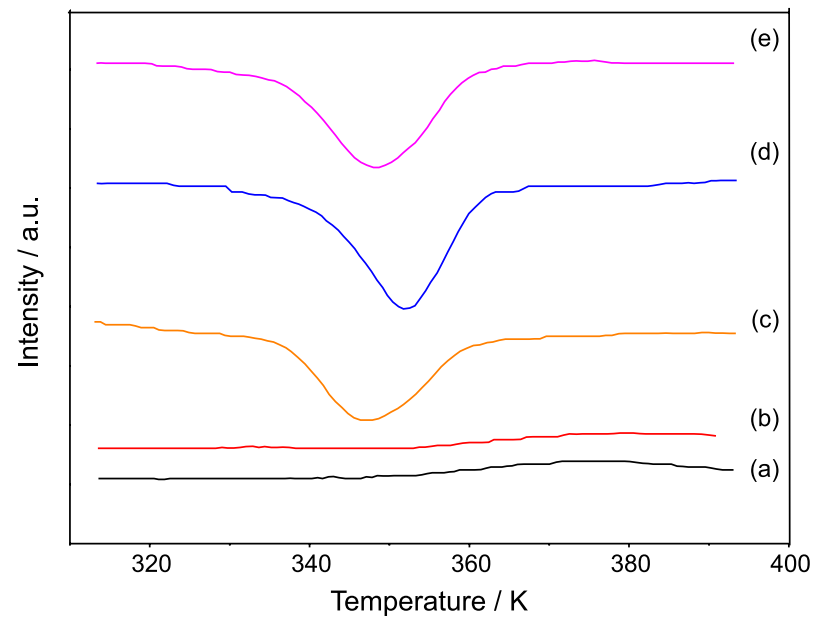

Figure 3. TPR profiles of $\mathrm{Pd} / \mathrm{Al}_{2} \mathrm{O}_{3}$ catalysts (a) A, (b) B, (c) C, (d) D and (e) E.

Table 2. Peak areas of hydrogen from decomposition of $\beta$-palladium hydride of $\mathrm{Pd} / \mathrm{Al}_{2} \mathrm{O}_{3}$ catalyst

\begin{tabular}{lccccc}
\hline Catalyst & A & B & C & D & E \\
\hline Particle size / nm & 1.0 & 2.7 & 4.0 & 6.9 & 6.5 \\
Peak area / a.u. & - & - & 18.42 & 22.07 & 23.48 \\
\hline
\end{tabular}

\section{Catalysts performance}

AAQ hydrogenation rates are presented in two different formats in Figure 4. In Figure 4a, the hydrogen peroxide yield obtained under different conditions is normalized per surface atoms of palladium to yield the TOF. In Figure 4b, the hydrogen peroxide yield obtained was normalized per total mass of palladium to obtain STY. From this, Pd particle and time on stream were considered to influence the activities. Also, the activities are reported by the initial conversion after 1 and $2 \mathrm{~h}$ on stream in both Figures.

As seen in Figure 4a, the initial TOF of AAQ hydrogenation increases with particle size from 1 to $7 \mathrm{~nm}$, which fit the pattern of antipathetic sensitivity. It has been
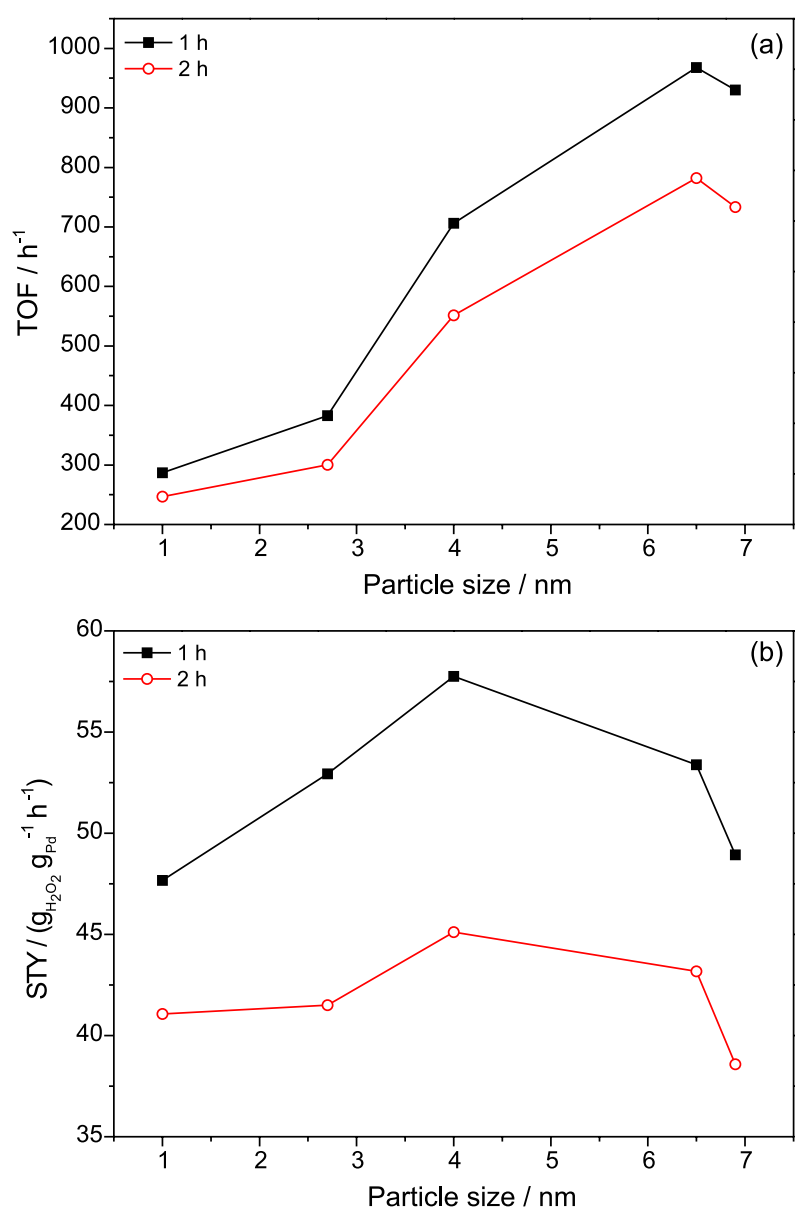

Figure 4. AAQ (a) turnover frequencies (TOF) and (b) space time yield (STY) over $\mathrm{Pd} / \mathrm{Al}_{2} \mathrm{O}_{3}$ catalysts A-E as a function of $\mathrm{Pd}$ particle size and time on stream at $318 \mathrm{~K}, 0.3 \mathrm{MPa}, \mathrm{G} / \mathrm{L}=10$ and $\mathrm{LHSV}=48 \mathrm{~h}^{-1}$. 
reported that the carbonyl $\mathrm{C}=\mathrm{O}$ group was activated via the interaction of lone pair of $\mathrm{C}=\mathrm{O}$ electrons. ${ }^{22}$ As mentioned before, the class I surface sensitivity appears more often in reactions with the activation of the $\pi$-bonds. It is due to that more energy is needed to activate the $\pi$-bonds. Therefore, metal clusters with a certain amount of atoms and specific packing structures including step-edge sites and defects are necessary for these reactions. AAQ hydrogenation mainly involves the activation of molecular $\pi$-bonds in $\mathrm{C}=\mathrm{O}$, which also requires a reaction center with a unique configuration of several metal atoms and step-edge sites. It is hard for small particles to supply enough atoms to form reaction center. So the reaction intrinsic rate sharply decreased when particle size decreased below $4 \mathrm{~nm}$.

Moreover, the higher TOF obtained by large Pd particles could be ascribed to the formation of the $\beta$-hydride which acts as a hydrogen reservoir. ${ }^{33}$ As shown in Figure 3, only a negative peak centered at $348 \mathrm{~K}$ appears in the TPR profile indicating hydrogen evolution which is attributed to the Pd $\beta$-hydride decomposition. ${ }^{34}$ Moreover, the amount of hydrogen evolved from the individual peaks was in accordance with the trend of the corresponding Pd average particle size. Santacesaria et al. ${ }^{1}$ reported that the overall reaction rate of anthraquinone hydrogenation was dominated by the mass transfer rate, while in the same reaction condition the difference of mass transfer was negligible. We suggest that the formation of the $\beta$-hydride acting as a hydrogen reservoir leads to the catalytic behavior of palladium in this reaction. Therefore the absorption of $\mathrm{H}_{2}$ and the Pd particle size have great impact on AAQ hydrogenation intrinsic rate.

However, in Figure 4b, the trend of STY is totally different from that of TOF. As the particle size increases, the STY per mass of palladium first increases and then decreases. This can be ascribed to the decrease of the surface active metal site number caused by particle growth. As the intrinsic reaction rate and the number of active sites change inversely with the Pd particle size, the maximum STY per mass of palladium is yielded at a medium particle size (4 $\mathrm{nm}$ as observed in Figure $4 \mathrm{~b}$ ).

Except for the active anthraquinone, the formation of other degradation products in the hydrogenation/oxidation process cycle contributes nothing but a loss of active quinones, and may gradually reduce the activity of catalysts or even deactivate the catalysts. Therefore, the selectivity of catalyst towards active quinones is also a key parameter in $\mathrm{H}_{2} \mathrm{O}_{2}$ production by anthraquinone method. Figure 5 shows the selectivity of catalysts B and D. Both catalysts exhibit an increase in selectivity by extending the reaction time. However, catalyst B showed a higher selectivity compared with catalyst $D$. This may be ascribed to the bigger particles activating $\mathrm{C}=\mathrm{O}$ bond more easily, and the generation of the main side reaction products such as anthrone also need the activation of the $\mathrm{C}=\mathrm{O}$ bond or the aromatic ring, which may require reaction centers with a unique configuration similar to AAQ hydrogenation. Moreover, the deactivation rate of catalyst with larger Pd particle size is faster (Figure 5 inset) which may also be caused by severe side reactions.

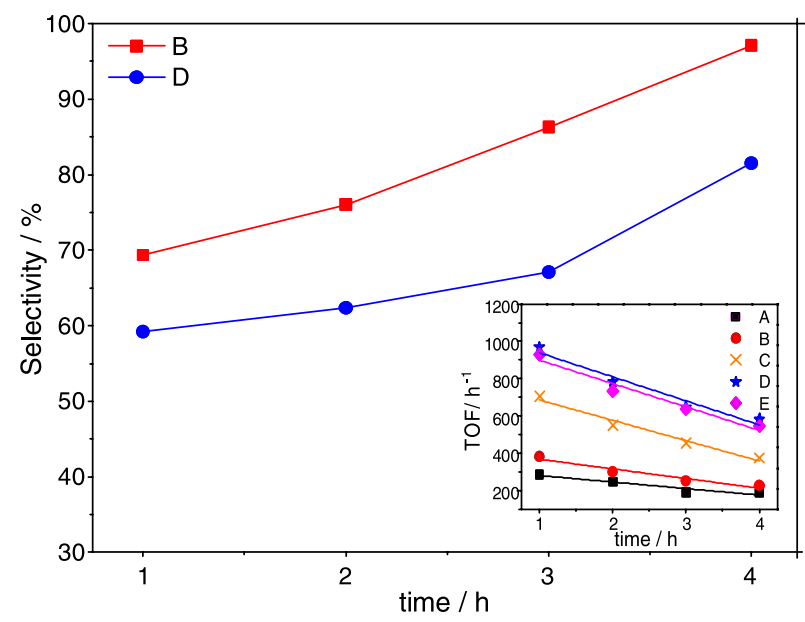

Figure 5. AAQ hydrogenation selectivities over $\mathrm{Pd} / \mathrm{Al}_{2} \mathrm{O}_{3}$ catalysts $\mathrm{B}$ and D. Inset: linear fitting of TOF for $\mathrm{Pd} / \mathrm{Al}_{2} \mathrm{O}_{3}$ catalysts A-E (time on stream at $318 \mathrm{~K}, 0.3 \mathrm{MPa}, \mathrm{G} / \mathrm{L}=10$, LHSV $=48 \mathrm{~h}^{-1}$ ).

\section{Conclusions}

Highly dispersed Pd catalysts prepared from polyol method were applied for studying the size effect during AAQ hydrogenation. The difference in reflux time and calcination temperature was used to control the particle size. TOF was found to increase from 286.8 up to $929.9 \mathrm{~h}^{-1}$ with the Pd particle size increase in the range of 1-7 nm after $1 \mathrm{~h}$. A diameter of $4 \mathrm{~nm}$ was found to be optimal in view of STY. The catalysts containing bigger Pd particles were poorly selective and deactivated faster than the catalyst with smaller Pd particles. Given the antipathetic structure sensitivity, a reaction mechanism based on the activation of the $\mathrm{C}=\mathrm{O}$ bond on reaction center with a unique configuration and the formation of the $\beta$-hydride acting as a hydrogen reservoir was proposed.

\section{Acknowledgments}

Supported by the National Natural Science Foundation of China (21306184).

\section{References}

1. Santacesaria, E.; Di Serio, M.; Velotti, R.; Leone, U.; Ind. Eng. Chem. Res. 1994, 33, 277. 
2. Campos-Martin, J. M.; Blanco-Brieva, G.; Fierro, J. L. G.; Angew. Chem., Int. Ed. 2006, 45, 6962.

3. Samanta, C.; Appl. Catal., A 2008, 350, 133.

4. Guo, Z.; Feng, J.; Feng, Y.; Evans, D. G.; Li, D.; Appl. Catal., A 2011, 401, 163.

5. Yang, S. I.; Yoo, K. K.; Kim, Y. I.; Shin, T. H.; Kim, D. Y.; Seo, S. K.; Chung, R. S.; Baik, D. S.; WO pat. 20100110102010.

6. Kosydar, R.; Drelinkiewicz, A.; Lalik, E.; Gurgul, J.; Appl. Catal., A 2011, 402, 121.

7. Santacesaria, E.; Di Serio, M.; Russo, A.; Leone, U.; Velotti, R.; Chem. Eng. Sci. 1999, 54, 2799.

8. Shen, C.; Wang, Y. J.; Xu, J. H.; Lu, Y. C.; Luo, G. S.; Chem. Eng. J. 2011, 173, 226.

9. Kosydar, R.; Drelinkiewicz, A.; Ganhy, J. P.; Catal. Lett. 2010, 139, 105.

10. Feng, J.-T.; Wang, H.-Y.; Evans, D. G.; Duan, X.; Li, D.-Q.; Appl. Catal., A 2010, 382, 240.

11. Li, Y.; Shen, W.; Sci. China: Chem. 2012, 55, 2485.

12. Benkhaled, M.; Morin, S.; Pichon, C.; Thomazeau, C.; Verdon, C.; Uzio, D.; Appl. Catal., A 2006, 312, 1.

13. Bigall, N. C.; Hartling, T.; Klose, M.; Simon, P.; Eng, L. M.; Eychmuller, A.; Nano Lett. 2008, 8, 4588.

14. Binder, A.; Seipenbusch, M.; Muhler, M.; Kasper, G.; J. Catal. 2009, 268, 150.

15. Crespo-Quesada, M.; Yarulin, A.; Jin, M.; Xia, Y.; KiwiMinsker, L.; J. Am. Chem. Soc. 2011, 133, 12787.

16. Lee, S.; Lee, B.; Mehmood, F.; Seifert, S.; Libera, J. A.; Elam, J. W.; Greeley, J.; Zapol, P.; Curtiss, L. A.; Pellin, M. J.; Stair, P. C.; Winans, R. E.; Vajda, S.; J. Phys. Chem. C 2010, 114, 10342.

17. Müller, C. A.; Maciejewski, M.; Koeppel, R. A.; Baiker, A.; Catal. Today 1999, 47, 245.

18. Englisch, M.; Jentys, A.; Lercher, J. A.; J. Catal. 1997, 166, 25.

19. Dantas Ramos, A. L.; da Silva Alves, P.; Aranda, D. A. G.; Schmal, M.; Appl. Catal., A 2004, 277, 71.
20. Zhou, W. P.; Lewera, A.; Larsen, R.; Masel, R. I.; Bagus, P. S.; Wieckowski, A.; J. Phys. Chem. B 2006, 110, 13393.

21. Van Santen, R. A.; Acc. Chem. Res. 2009, 42, 57.

22. Hammer, B.; Nørskov, J. K. In Advances in Catalysis, vol. 45; Bruce, H. K.; Gates, C., eds.; Academic Press: Waltham, 2000.

23. Xiao, C. X.; Cai, Z. P.; Wang, T.; Kou, Y.; Yan, N.; Angew. Chem., Int. Ed. 2008, 47, 746.

24. Bielawa, H.; Hinrichsen, O.; Birkner, A.; Muhler, M.; Angew. Chem., Int. Ed. 2001, 40, 1061.

25. Honkala, K.; Hellman, A.; Remediakis, I. N.; Logadottir, A.; Carlsson, A.; Dahl, S.; Christensen, C. H.; Norskov, J. K.; Science 2005, 307, 555.

26. Overbury, S. H.; Schwartz, V.; Mullins, D. R.; Yan, W.; Dai, S.; J. Catal. 2006, 241, 56.

27. Ruta, M.; Semagina, N.; Kiwi-Minsker, L.; J. Phys. Chem. C 2008, 112, 13635.

28. Bartholomew, C. H. F.; Farrauto, R. J.; Fundamentals of Industrial Catalytic Processes; John Wiley \& Sons: Hoboken, 2006.

29. Tonetto, G. M.; Damiani, D. E.; J. Mol. Catal. A: Chem. 2003, 202, 289.

30. Drelinkiewicz, A.; Waksmundzka-Gora, A.; Makowski, W.; Stejskal, J.; Catal. Commun. 2005, 6, 347.

31. Zheng, J.; Guo, M.; Song, C.; Fuel Process. Technol. 2008, 89, 467.

32. Boudart, M.; Hwang, H. S.; J. Catal. 1975, 39, 44.

33. Benedetti, A.; Fagherazzi, G.; Pinna, F.; Rampazzo, G.; Selva, M.; Strukul, G.; Catal. Lett. 1991, 10, 215.

34. Amorim, C.; Keane, M. A.; J. Colloid Interface Sci. 2008, 322, 196.

Submitted: July 2, 2015

Published online: January 13, 2016 